\title{
Newly characterised ex vivo colospheres as a three-dimensional colon cancer cell model of tumour aggressiveness
}

\author{
L-B Weiswald', S Richon', P Validire ${ }^{2}$, M Briffod $^{3}$, R Lai-Kuen $^{4}$, FP Cordelières ${ }^{5}$, F Bertrand $^{3}$, D Dargere', \\ G Massonnet', E Marangoni', B Gayet ${ }^{7}$, M Pocard $^{8,9}$, I Bieche $^{1,10}$, M-F Poupon $^{6}$, D Bellet ${ }^{1,11}$ and \\ V Dangles-Marie ${ }^{*, I}$
}

'IFR7I Sciences du Médicament, Faculté des Sciences Pharmaceutiques et Biologiques, Université Paris Descartes, 4 avenue de l'Observatoire, F-75006 Paris, France; ' ${ }^{2}$ épartement d'Anatomie Pathologique, Institut Mutualiste Montsouris, 42 boulevard Jourdan, F-750 I 4 Paris, France; ${ }^{3}$ Service d'Anatomie et de Cytologie Pathologiques, Centre René Huguenin, 35 rue Dailly, F-922 I 0 Saint Cloud, France; ${ }^{4}$ Plateforme d'Imagerie Cellulaire et Moléculaire, IFR7 I Sciences du Médicament, Faculté des Sciences Pharmaceutiques et Biologiques, Université Paris Descartes, 4 avenue de l'Observatoire, F-75006 Paris, France; ${ }^{5}$ Plateforme Imagerie Cellulaire et Tissulaire, Research Center, Institut Curie, 26 rue d'Ulm, F-75005 Paris, France; ${ }^{6}$ Département du Transfert, Hôpital Institut Curie, 26 rue d'Ulm, F-75005 Paris, France; ${ }^{7}$ Département Médico-Chirurgical de Pathologie Digestive, Institut Mutualiste Montsouris, 42 boulevard Jourdan, F-750 4 Paris, France; ${ }^{8}$ Département Médico-Chirurgical de Pathologie Digestive Chirurgie, Hôpital Lariboisière, 2 rue Ambroise Paré, F-750 I 0 Paris, France; 'UMR U965 INSERM/Paris7 Université Paris Diderot, Hôpital Lariboisière, F-750 I 0 Paris, France; ${ }^{10}$ UMR745 INSERM, Faculté des Sciences Pharmaceutiques et Biologiques, Université Paris Descartes, 4 avenue de l'Observatoire, F-75006 Paris, France; "'Service de Médecine Nucléaire, Centre René Huguenin, 35 rue Dailly, F92210 Saint Cloud, France

\begin{abstract}
BACKGROUND: New models continue to be required to improve our understanding of colorectal cancer progression. To this aim, we characterised in this study a three-dimensional multicellular tumour model that we named colospheres, directly obtained from mechanically dissociated colonic primary tumours and correlated with metastatic potential.

METHODS: Colorectal primary tumours $(n=203)$ and 120 paired non-tumoral colon mucosa were mechanically disaggregated into small fragments for short-term cultures. Features of tumours producing colospheres were analysed. Further characterisation was performed using colospheres, generated from a human colon cancer xenograft, and spheroids, formed on agarose by the paired cancer cell lines.

RESULTS: Colospheres, exclusively formed by viable cancer cells, were obtained in only I day from 98 tumours (47\%). Inversely, nontumoral colonic mucosa never generated colospheres. Colosphere-forming capacity was statistically significantly associated with tumour aggressiveness, according to AJCC stage analysis. Despite a close morphology, colospheres displayed higher invasivity than did spheroids. Spheroids and colospheres migrated into Matrigel but matrix metalloproteinase (MMP)-2 and MMP-9 activity was detected only in colospheres. Mouse subrenal capsule assay revealed the unique tumorigenic and metastatic phenotype of colospheres. Moreover, colospheres and parental xenograft reproduced similar CD44 and CDI 33 expressions in which CD44 ${ }^{+}$cells represented a minority subset of the CDI33+ population.

CONCLUSION: The present colospheres provide an ex vivo three-dimensional model, potentially useful for studying metastatic process. British Journal of Cancer (2009) I 0 I, 473-482. doi:I0.1038/sj.bjc.6605 I73 www.bjcancer.com

Published online 14 July 2009

(c) 2009 Cancer Research UK
\end{abstract}

Keywords: colospheres; colorectal cancer; three dimension; ex vivo model; metastasis

Colorectal cancer (CRC) is a major cause of morbidity and mortality worldwide, and CRC patient death is generally attributable to metastasis development and resistance to chemotherapy. Human CRC is one of the most extensively investigated tumour types, and genetic pathways involved in these malignancies have been identified (Fearon and Vogelstein, 1990). However, complex factors involved in CRC metastasis remain largely undefined and there is a need for effective drugs for treatment. In this context, successful future treatments must rely on a comprehensive

\footnotetext{
*Correspondence: Dr V Dangles-Marie, IFR7I Sciences du Médicament, Université Paris Descartes, 4 avenue de l'Observatoire, Paris F-75006, France; E-mail: virginie.dangles@parisdescartes.fr
}

Received 5 February 2009; revised 2 June 2009; accepted 5 June 2009; published online 14 July 2009 analysis of events underlying the metastatic process, together with the development of new model systems that could be easily manipulated so as to evaluate the efficacy of novel therapeutics. The importance of studying cancer cells in 3D has been recently emphasised because of their higher relevance for an in vivo situation (Jacks and Weinberg, 2002; O’Brien et al, 2002; Yamada and Clark, 2002; Debnath and Brugge, 2005; Smalley et al, 2006). For this purpose, some permanent cancer cell lines, including colon cancer cell lines, are able to form spheroids when cultured in non-adherent conditions (for review, Friedrich et al, 2007). These spheroids are recognised to mimic microtumours more closely than cancer cell line monolayers and have been used mainly in chemo- and radioresistance studies. Another 3D cell model aims at promoting the expansion of cancer stem cells from solid tumour tissue after enzymatic dissociation in single-cell suspensions. This 
approach, first described for the expansion of normal or cancer brain cell in neurospheres (Svendsen et al, 1998), required a specific culture protocol and, in the case of CRC, led to the colon cancer sphere model (Ricci-Vitiani et al, 2007; Todaro et al, 2007; Vermeulen et al, 2008).

In this study, carried out on a series of 203 CRC primary tumours, we describe a model of 3D cellular structures spontaneously generated after an ex vivo mechanical dissociation of CRC tissue. We refer to these 3D structures as colospheres. To further characterise these colospheres, we used a human colon cancer xenograft, XenoCT320, and the derived paired colon cancer cell lines, CT320X6 and CT320 (Dangles-Marie et al, 2007). Colospheres generated from xenograft tissue and spheroids formed on agarose from colon cancer cell lines were then studied in parallel.

\section{MATERIALS AND METHODS}

\section{Patients and tissue specimens}

The CRC primary tumours were collected from the Institut Mutualiste Montsouris (Paris, France) and the Institut Gustave Roussy (Villejuif, France) from 203 patients observed between May 2003 and May 2006, in accordance with protocols approved by the local ethical committees and with the Helsinki Declaration of 1975, as revised in 1983.

Tumour material not required for histopathological diagnosis was placed in a 'culture medium' (DMEM supplemented with $10 \%$ decomplemented FCS, $10 \mathrm{mmoll}^{-1}$ HEPES, $4.5 \mathrm{gl}^{-1}$ glucose, $1 \mathrm{mmol}^{-1}$ pyruvate sodium, $200 \mathrm{U} \mathrm{ml}^{-1}$ penicillin and $200 \mu \mathrm{g} \mathrm{ml}^{-1}$ streptomycin) and submitted to ex vivo mechanical mincing.

\section{Colosphere-forming assay}

Tissue fragments of approximately $0.5 \times 0.5 \times 0.5 \mathrm{~cm}$ were submitted to mechanical dissociation in Petri dishes: after a medium washing step, tissue sample was first finely cut with a scalpel blade and then crushed with a striated plunger from a disposable syringe. The resulting pieces were transferred to a $25-\mathrm{cm}^{2}$ culture flask containing the 'culture medium' and incubated at $37^{\circ} \mathrm{C}$, in $8 \% \mathrm{CO}_{2}$.

Dissociated tumour cultures were scored by a double-blind light microscopical examination at $\times 10$ magnification by two different observers. A minimum of five fields per flask were viewed. Colosphere formation was scored on day 1 after culture as follows: $(-)$, no colosphere observed; $(+), \leqslant 2$ colospheres per field; $(++),>2$ colospheres per field.

\section{Xenograft and spheroid culture}

XenoCT320 xenograft, CT320 and CT320X6 cell lines have been previously described (Dangles-Marie et al, 2007). For xenograft passage, tumour fragments were subcutaneously grafted in the interscapular region into 5-week-old athymic nude female mice (Harlan, Winkelmann, Germany) bred and maintained in specified pathogen-free conditions (protocol approval no P2.VDM.026.07, local ethical committee on animal experiments, CREEA René Descartes, Paris, France).

For spheroid culture, tumour cells grown as a monolayer were resuspended with trypsin, and $5 \times 10^{3}$ cells were seeded in microwells coated with $1 \%$ agarose so as to obtain, after 3 days, a single spheroid per well.

\section{D multipositioning light videomicroscopy}

Colosphere and spheroid development was monitored by timelapse video microscopy for $65 \mathrm{~h}$ at a $4 \mathrm{~min}$ interval. Dynamic sequences were obtained on a DM IRBE stand equipped with a motorised stage (Leica, Mannheim, Germany) using a $37^{\circ} \mathrm{C} 8 \%$
$\mathrm{CO}_{2}$-humidified stage-top incubator (Life Imaging Services, Basel, Switzerland).

\section{Histological characterisation}

Colospheres and spheroids were embedded using the Cytoblock method (Briffod et al, 2000) and the Shandon kit (Thermo electron corporation, Saint Herblay, France). Immunostaining was performed on the resulting paraffin sections using an automated immunostainer (Ventana, Strasbourg, France) with mAb to Ki67 antigen (MIB1 clone; Dako, Trappes, France) and to E-cadherin (4A2C7 clone; Zymed, Montrouge, France). At least eight independent samples were collected for the specific analysis of colospheres and spheroids.

\section{TBP gene expression}

Specific mouse TBP gene expression and the expression of both the mouse and the human TBP genes were studied by real-time quantitative RT - PCR (Lévy et al, 2004) to determine the quantity of mouse cells in human xenografts and colospheres. With the assistance of the computer program Oligo 5.0 (National Biosciences, Plymouth, MN, USA), the murine Tbp primer pair was selected to be mouse specific when compared with the sequence of the human TBP gene, whereas the total TBP primer pair was selected to amplify both the mouse and the human TBP genes. BLASTN searches against dbEST and $\mathrm{nr}$ (the non-redundant set of the GenBank, EMBL and DDBJ database sequences) were conducted to confirm the total gene specificity of the nucleotide sequences chosen for the primers and for the absence of DNA polymorphisms. The nucleotide sequences of the primers used were the following: Mm-TBP-U (5'-CCCTTGTACCCTTCACCAA TGAC- $\left.3^{\prime}\right)$ and Mm-TBP-L (5'-TCACGGTAGATACAATATTTTG AAGCTG- $\left.3^{\prime}\right)$ and Total-TBP-U (5'-TGCACAGGAGCCAAGAGTG AA- $3^{\prime}$ ) and Total-TBP-L (5'-CACATCACAGCTCCCCACCA- $3^{\prime}$ ). The thermal cycling conditions comprised an initial denaturation step at $95^{\circ} \mathrm{C}$ for $10 \mathrm{~min}$, and 50 cycles at $95^{\circ} \mathrm{C}$ for $15 \mathrm{~s}$ and $65^{\circ} \mathrm{C}$ for $1 \mathrm{~min}$.

Results, expressed as $N$-fold differences in the specific murine Tbp gene expression (using Mm-TBP primers), relative to the sum of the mouse and the human TBP gene expression (using TotalTBP primers), termed $\mathrm{N} M m-T B P$, are determined by the formula: $\mathrm{N} M m-T B P=2^{\Delta C \text { tsample }}$. The $\Delta C_{\mathrm{t}}$ value of the sample is determined by subtracting the $C_{t}$ value of the murine TBP gene from the $C_{\mathrm{t}}$ value of the total (mouse + human) TBP gene. The NMm-TBP values of the samples are subsequently normalised such that the median of the NMm-TBP values of four mouse tissues was 100. As $T B P$ is a ubiquitously expressed housekeeping gene, which encodes the TATA box-binding protein, a component of the DNA-binding protein complex TFIID, and shows a similar expression in our human and mouse tissues $\left(C_{\mathrm{t}}=27\right.$ for $\left.5 \mathrm{ng} \mathrm{cDNA}\right)$, the final result (normalised NMm-TBP value) determines the proportion of mouse cell contamination for a given sample.

\section{Electron microscopy}

After harvesting, colospheres and spheroids were analysed using standard techniques for transmission electron microscopy (Ribadeau Dumas et al, 2004). Ultrathin sections were examined at $80 \mathrm{kV}$ using a JEOL JEM-1005 electron microscope (JEOL S.A., Croissy-sur-Seine, France). For scanning electron microscopy (SEM), cells were critical-point dried in hexamethyldisilizane (Sigma-Aldrich, Saint-Quentin, France). Samples were mounted on specimen stubs, sputter coated with gold using JEOL JCF100 and examined at $16 \mathrm{kV}$ using JEOL ISM-35CF. At least six samples for CT320X6 and CT320 spheroids and for XenoCT320 colospheres were submitted to electron microscopy examination. 


\section{In vivo tumorigenicity assay}

The tumorigenicity of XenoCT320 colospheres, CT320X6 spheroids and CT320X6 single cells was compared in a subrenal capsule assay in nude mice. Three days after xenograft tissue dissociation, colospheres of $100-150 \mu \mathrm{m}$ diameter were manually collected under the microscope and an aliquot was trypsinised to estimate the number of viable cells in the colospheres. The concentration was adjusted to have a number of colospheres equivalent to $4 \times 10^{4}$ cells per $10 \mu \mathrm{l}$ for intrarenal injection. Similarly, eight spheroids formed by seeding $5 \times 10^{3}$ cells per microwell were injected in $10 \mu \mathrm{l}$. As spheroids from this cell line grow slowly, spheroids collected 3 days after initiation contained about 5000 cells per spheroid for a diameter of about $150 \mu \mathrm{m}$. An oblique incision was made on the skin parallel to the long axis of the right kidney in anaesthetised mice (xylazin/ketamin protocol). Injections of cells equivalent to $4 \times 10^{4}$ cells were administered with a $27 \mathrm{G}$ needle in the subcapsular space in the right kidney. The internal diameter of the $27 \mathrm{G}$ needles is $200 \mu \mathrm{m}$ at the minimum, which would avoid any damage on spheroids and colospheres. After cell injection, the kidney was then returned to the peritoneal space and the skin was closed with surgical staples. The recipient mice were necropsied at 14 weeks after injection and kidneys, spleen, lung and liver were removed for histological examination.

Tumorigenicity of the CT320X6 cell line was carried out in parallel in nude mice by the subcutaneous transplantation of $2 \times 10^{6}$ viable cells in $0.2 \mathrm{ml}$ of PBS. The mice were observed for 2 months for the appearance of tumour development.

\section{Matrigel assay}

Colospheres and spheroids were added to Matrigel solution $\left(3 \mathrm{mg} \mathrm{ml}^{-1}\right.$ ) (BD Biosciences, Le Pont de Claix, France) in 24-well plates before polymerisation of the lattice. Culture medium was added to the Matrigel layer.

\section{Gelatin zymography}

Gelatin zymography assays were performed with a Bio-Rad laboratories kit (Marnes La Coquette, France), according to the manufacturer's instructions. Colospheres, spheroids and xenograft tissue were lysed with zymogram sample buffer and the amount of protein was estimated using the Bradford method (Biorad Dc Protein Assay; Bio-Rad Laboratories). Twenty micrograms of protein from each sample was separated on polyacrylamide gels containing $10 \%$ gelatin. After electrophoresis, the gels were washed in renaturation buffer for $30 \mathrm{~min}$, and incubated overnight at $37^{\circ} \mathrm{C}$ in the development buffer. Gels were stained with a Coomassie blue R250 $0.5 \%$ solution and destained with $3 \times$ destaining solution.

\section{Flow cytometric analysis}

Disaggregated colospheres, spheroids and xenografts were assessed using an Epics XL cytometre (Coulter, Villepinte, France) with the following antibodies: anti-human CD133/2 (clone 293C3) phycoerythrin, anti-human EpCAM (clone HEA-125) fluorescein isothiocyanate (Miltenyi-Biotec SAS, Paris, France) and antihuman CD44-FITC (clone G44-26; BD Biosciences), at appropriate dilutions. As for xenograft tissue, human colon cancer cells were magnetically labelled and separated from mouse stroma cells using human EpCAM microbeads (Miltenyi-Biotec SAS) according to the manufacturer's instructions, before assessment by flow cytometry.

\section{Confocal microscopy}

About 30 colospheres in suspension were fixed for $3 \mathrm{~h}$ at $4^{\circ} \mathrm{C}$ in PBS containing 4\% PFA, followed by washes in PBS. Colospheres were then permeabilised in $1 \%$ Triton X-100 in PBS for $1 \mathrm{~h}$ and washed with PBS. After a $1 \mathrm{~h}$ incubation in $\mathrm{PBS} / \mathrm{NH}_{4} \mathrm{Cl}$ $\left(50 \mathrm{mmoll}^{-1}\right)$, followed by washes in PBS, colospheres were saturated overnight with $3 \%$ BSA in PBSt $(0.1 \%$ Triton $\mathrm{X}-100$ in PBS) at $4^{\circ} \mathrm{C}$ and washed in PBSt. Colospheres were incubated for $24 \mathrm{~h}$ at $4^{\circ} \mathrm{C}$ with anti-human EpCAM-FITC (clone HEA-125) in PBSt (dilution 1:50) and rinsed with PBSt. The DNA marker, TOPRO-3 (Invitrogen-Molecular Probes, Cergy Pontoise, France), was then applied for $20 \mathrm{~min}$ at room temperature. Colospheres were mounted in glycerol/PBS (90/10: v/v). Images were recorded on a Leica TCS SP2 confocal microscope.

\section{RESULTS}

\section{Observation of colospheres within ex vivo dissociated colon primary tumours}

Dissociation of 203 fresh colon primary tumour tissues directly harvested from human patients undergoing surgery led to the formation of spherical organoid structures, which we named colospheres (Figure 1A), in 98 out of the 203 specimens $(47 \%)$ in just 1 day. Colospheres displayed a diameter comprised between 20 and $200 \mu \mathrm{m}$ and were easily identifiable because of their smooth refringent outline. To determine whether the property to form such colospheres from patient tumours was a feature restricted to cancer tissue, the same mechanical dissociation protocol was carried out in parallel with non-tumoral colon tissue counterparts from 120 of these 203 tumour tissues. It is noteworthy that no colospheres were ever observed after dissociation of nonneoplastic colonic mucosa, showing that these spherical structures are only generated by cancer tissue. Among these 98 specimens, 28 tumours led to the generation of a large number of colospheres.

Colospheres formed by highly compacted cells were resistant to mechanical disruption. On the basis of haemalun-eosin-safran (HES) staining, only carcinoma cells were observed in colospheres, whereas no stromal cells were recognised (Figure 1B), indicating that colospheres were structured aggregates of cancer cells and not merely globular fragments of tumour tissue. EpCAM staining performed with cytometry analyses or confocal microscopy confirmed the epithelial origin of colosphere-forming cells (Figure 1D-F). Anti-Ki67 immunostaining showed that colospheres contained viable proliferating cells (Figure 1C).

Tumour collection was divided into two groups: non-disseminated tumours (AJCC stage I and II) and disseminated tumours (AJCC stage III and IV), as AJCC stage I and II tumours differ from stage III and IV tumours by the fact that the latter group displays metastases in lymph nodes and/or in distant organs. Thus, the capacity of primary tumours to form colospheres was found to be significantly correlated with tumour aggressiveness. Indeed, statistical analysis showed that the stage III and IV tumour groups gave rise more frequently to colospheres than did the stage I and II tumour groups $(P<0.01$; Figure 2$)$.

\section{Colosphere morphology studies}

For a further characterisation of colospheres, the production of a large quantity of reproducible biological material was required. For this purpose, we used human colon cancer xenograft XenoCT320, previously established from a human primary tumour (DanglesMarie et al, 2007). The tumour fragment F320 leading to the XenoCT320 establishment came from a patient who presented synchronous liver metastasis. In nude mice, axiliar lymph nodes were tumour positive when collected after the removal of the tumour xenograft and recurrence at the original engraftment site was observed (data not shown). Similar to the parent colon cancer specimen, which was included in the former clinical study, XenoCT320 tissue generated colospheres after ex vivo mechanical 

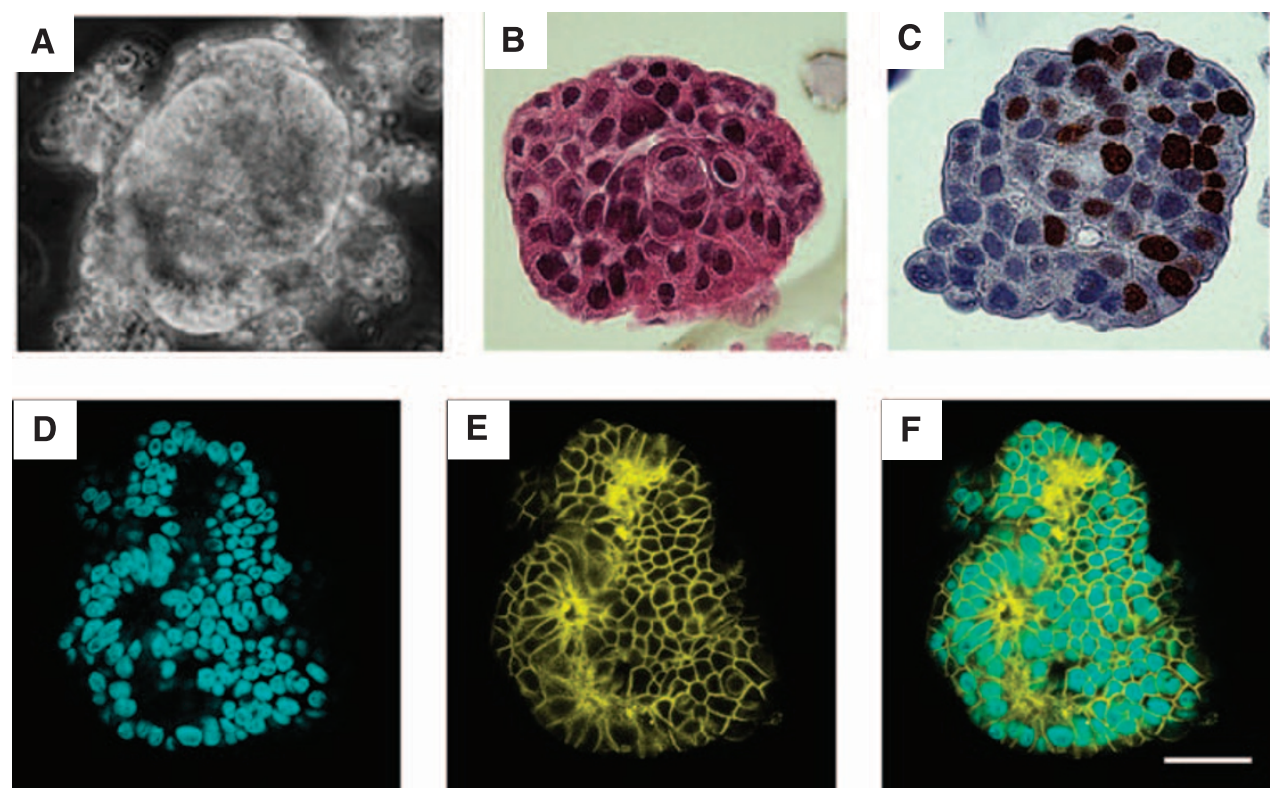

Figure I Colospheres derived from colon carcinoma patient tissue. (A) Photomicrograph of a representative colosphere generated on tissue culture plastic; (B) HES staining; (C) anti-Ki67 staining. Magnification: $\times$ 40. (D-F) Confocal immunofluorescence of colospheres. (D) TOPRO-3 staining; (E) EpCAM staining; (F) overlay of $(\mathbf{D})$ and $(\mathbf{E})$. Scale bar: $50 \mu \mathrm{m}$.

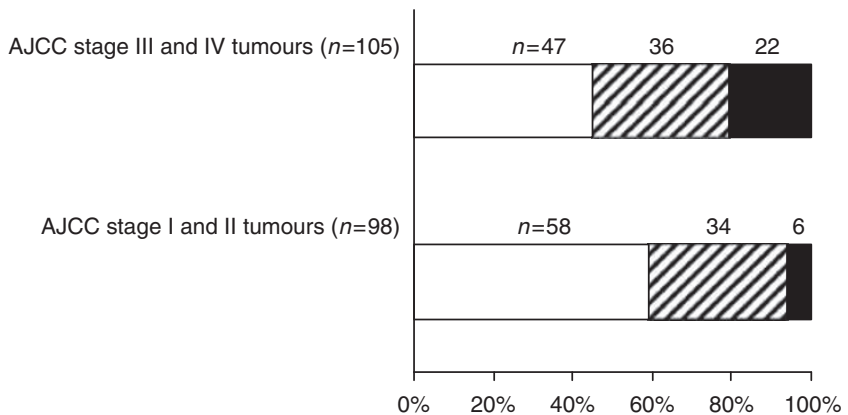

Figure 2 Colosphere formation is associated with tumour aggressiveness. Figure showing the number of primary tumours giving rise to many colospheres ('+ +', $\mathbf{0})$, a few colospheres (' + ', $\mathbf{E})$ or no colosphere $('-,, \square)$ in non-disseminated tumours (AJCC stages I and II) and in disseminated tumours (AJCC stages III and IV). Colosphere formation was scored as described in Materials and Methods.

dissociation. Furthermore, the morphological features of colospheres are close to those of spheroids generated in vitro using permanent carcinoma cell lines. This prompted us to compare XenoCT320 colospheres with spheroids derived from the CT320X6 cell line, previously established from the XenoCT320 tumour, and with spheroids derived from the CT320 cell line, established from the same original patient tumour fragment as the xenograft (Figure 3).

To analyse the dynamic nature of cellular events leading to colosphere formation in only 1 day, dissociated XenoCT320 tissue was filmed as a $2 \mathrm{D}$ outline every $4 \mathrm{~min}$ for $65 \mathrm{~h}$ (Figure 4 and Supplementary Video 1). This real-time monitoring clearly showed that large colospheres $(>50 \mu \mathrm{m})$ were generated by remodelling of tissue fragments, whereas smaller colospheres were spontaneously formed by the aggregation of single cells. Interestingly, the rapid generation of colospheres was not because of the presence of FCS, as similar experiments performed in FCS-free medium led to the same observation (data not shown).
Morphology studies were further investigated by SEM experiments that confirmed the high degree of compaction of these wellrounded structures (Figure $3 \mathrm{~A}$ ). Moreover, the outer surface of both colospheres and spheroids appeared quite smooth, in contrast to the thick filament network of extracellular matrix components entirely covering the surface of spheroids described for the human colon carcinoma HT29 cell line (Santini and Rainaldi, 1999). Using histological examination (Figure 3B), only cancer cells were observed in XenoCT320 colospheres. This observation was confirmed by cytometry analysis performed with anti-epithelial-specific human antigen EpCAM, which showed a consistent staining of all colosphere-forming cells. Real-time quantitative RT-PCR using primers specific for mouse Tbp confirmed the absence of mouse cells in human XenoCT320 colospheres, whereas this approach always showed the presence of mouse (stromal) cells in human XenoCT320 tumour tissue (rate $<10 \%)$. Although XenoCT320 colospheres mimicked adenocarcinoma, CT320X6 and CT320 spheroids resembled only carcinoma morphology. In addition, Ki-67 staining showed that colospheres were made up of viable proliferating cells. Viability assays confirmed that colospheres remained alive for up to a minimum of 3 weeks when transferred on agarose to avoid adherence to substrate (Supplementary Figure S1). However, the latter cells proliferated less strongly than did cells forming spheroids (Figure 3C).

\section{Migration and invasion properties of colospheres}

As the above results from 203 patient primary tumours showed a correlation between aggressiveness of the tumour and its ability to form numerous colospheres, we next investigated the migratory and invasive properties of colospheres. Carcinoma invasiveness is often characterised by an epithelial-to-mesenchymal transition (EMT)-like dedifferentiation of tumour cells, a process by which epithelial cell layers lose polarity and cell-cell contact and undergo remodelling of the cytoskeleton, leading to a migratory phenotype (Bates and Mercurio, 2005). The nature of the cellular junction and the expression of E-cadherin, a caretaker of EMT, were thus investigated in colospheres and spheroids. Using 
Moderately differentiated colon

adenocarcinoma F320

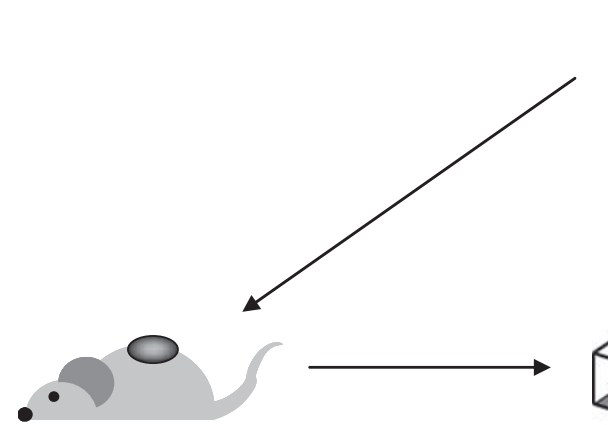

XenoCT320 xenograft established from F320

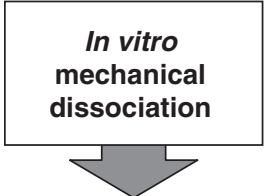

XenoCT320 colospheres

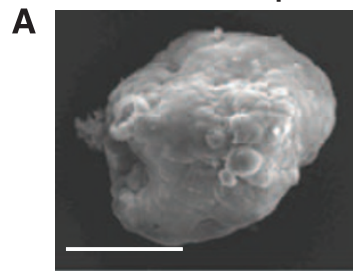

B

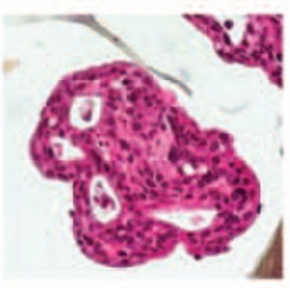

C

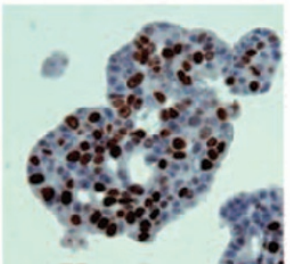

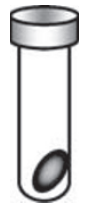

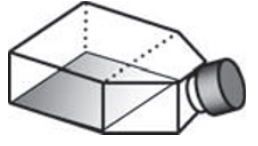

CT320X6 cell line established from XenoCT320

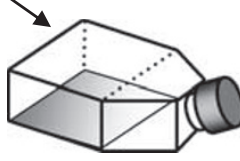

СT320 cell line established from F320

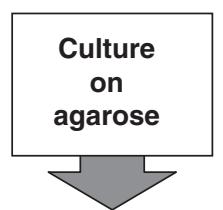

CT320X6 spheroids
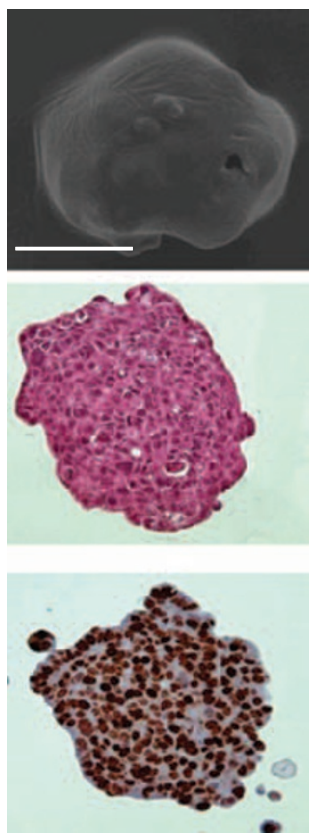

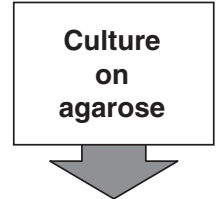

CT320 spheroids
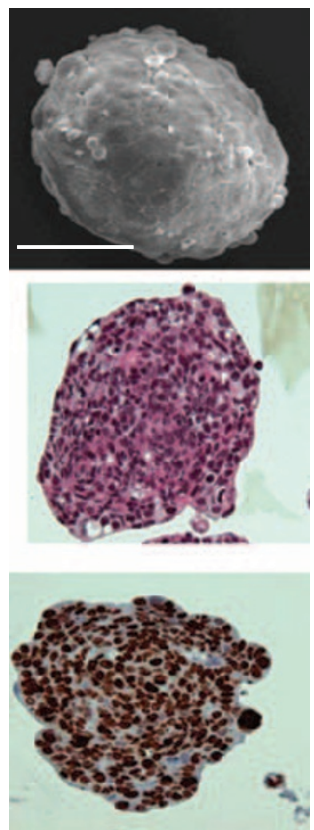

Figure 3 Experimental protocol leading to the production of XenoCT320 colospheres and paired spheroids of CT320X6 and CT320 cell lines. Colospheres (left panel), CT320X6 spheroids (middle panel) and CT320 spheroids (right panel) underwent SEM. (A) Bar = I00 $\mu$ m; HES staining (B); antiKi67 immunostaining $(\mathbf{C})$; magnification: $\times 20$.

electron microscopy, glandular structures with mucus, microvilli and desmosomes were found both in spheroids and colospheres, indicating a gut epithelial origin (Figure 5A). Nevertheless, zonula occludens, signs of tight junctions, were observed in spheroids but not in colospheres. E-cadherin immunostaining showed that membrane expression was more disturbed in colospheres than in spheroids (Figure 5B).

For functional analysis, colospheres and spheroids were embedded in Matrigel in the absence of a chemoattractant. Spherical multicellular cell aggregates were then imaged during 3 days in culture. Although colospheres and spheroids were shown above to be compacted structures using SEM, it was observed that single cells succeeded in detaching from colospheres in the
Matrigel assay (Figure 5C and Supplementary Figure S2A). As for spheroids, even if larger size of spheroid clusters was shown, no isolated cell could be observed (Figure 5C and Supplementary Figure S2B).

Movement into Matrigel requires extracellular matrix degradation. Two major matrix metalloproteinases (MMPs) in colon cancer, MMP-2 and MMP-9, were then studied using gelatin zymography. Although protein extracts of spheroids displayed no gelatinase activity, colospheres and xenograft exhibited both MMP-2 and MMP-9 activity (Figure 5D).

We then tested the biological features and metastatic characteristics of colospheres through the subrenal capsule implantation of a low and equivalent number of human colon cancer cells $\left(4 \times 10^{4}\right)$ 


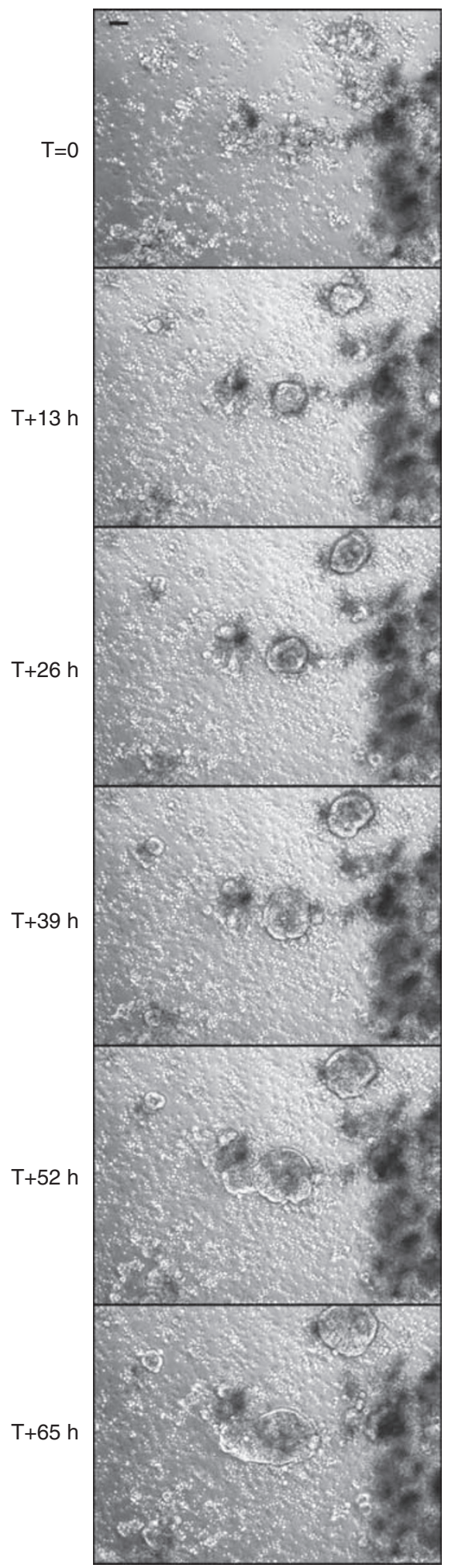

Figure 4 Genesis of XenoCT320 colospheres. Pictures, taken as representative of four independent experiments, at $T=0$ after tumour tissue dissociation, $T+13, T+26, T+39, T+52$ and $T+65 h$. $\mathrm{Bar}=100 \mu \mathrm{m}$

injected as XenoCT320 colospheres, as CT320X6 spheroids or as a cell suspension from the CT320X6 cell line (Figure 6A). The subcutaneous injection of a large number of CT320X6 cells $\left(2 \times 10^{6}\right.$ cells $)$ as single cells or spheroids proved that this cell line was tumorigenic in nude mice. Tumour formation at the injection site occurred in 6 out of 15 mice injected with XenoCT320 colospheres. Conversely, CT320X6 spheroids formed no tumour ( 0 out of 15) and in the CT320X6 single-cell suspension, only one local tumour was formed in 1 out of 13 cases. In addition, a gross and histological examination of potential organ distant sites revealed the unique tumorigenic and metastatic phenotype of the colospheres: metastases were only observed in the case of colosphere injection (Figure 6B).

\section{Expression of colon cancer stem cell markers by colospheres}

Floating spherical cell cluster cultures, such as colon cancer spheres, mammospheres and neurospheres, have been described as being valuable models for cancer stem cell culture. The round compact morphology of colospheres resembles that of colon cancer spheres. This observation and the fact that colospheres are more efficient than spheroids in the initiation of tumour growth and metastasis in immunodeficient mice led us to study the membrane expression of two cancer stem cell markers, CD133 and CD44, in XenoCT320 colospheres. We then compared this expression with that of human cancer cells in XenoCT320 tissue and with that of CT320X6 and CT320 spheroids (Table 1).

Colospheres, spheroids and carcinoma cells in xenograft highly expressed CD133. Even if the variability of the $\mathrm{CD}_{133}{ }^{+}$cell number was high in colospheres and xenografts according to SEM, the profile of this cell sub-population was similar in parental xenograft and derived colospheres. In contrast to CD133, CD44 was expressed to a weaker extent in human cancer cells in xenograft tissue and colospheres than in spheroids. All CD44 ${ }^{+}$ cells were $\mathrm{CD} 133^{+}$in colospheres and xenografts, whereas a subpopulation of $\mathrm{CD} 44^{+} / \mathrm{CD} 133^{-}$cells was present in spheroids. Furthermore, the CD133 and CD44 phenotype of colospheres remained stable even after 21 days of ex vivo culture (Flow cytometry data: $47.9 \% \pm 14 \mathrm{CD} 133^{+}$cells, $2.1 \% \pm 1.8 \mathrm{CD} 44+$ cells, at D21, three independent experiments).

\section{DISCUSSION}

This study reports the identification of colospheres, a newly characterised 3D cancer cell model directly obtained from dissociated human CRC tissue and associated with tumour aggressiveness. This model differs first from classical spheroids in that colospheres are obtained after short-term culture and not with permanent cell lines and, second, in that colospheres and spheroids clearly display distinct phenotype features.

The first step of this work was based on a large series of primary colon tumour specimens collected from 203 patients. After mechanical disruption, 98 tumours led to colospheres. A striking point is that the capacity to generate colospheres is not an intrinsic property of colon mucosa, which is not capable of generating colospheres. In contrast, only tumour epithelial cells are able to aggregate in a compact way to lead to spherical well-organised structures. The observation of such organoid structures has been reported by a limited number of studies aimed at establishing in vitro human colon cancer cell lines (McBain et al, 1984; Park et al, 1987; Oh et al, 1999) or in culture from glioma and bladder cancer biopsy specimens (Bjerkvig et al, 1992), but have never been studied further. We showed that the capacity to form colospheres was related to aggressiveness of the tumour, as defined by its AJCC stage. Indeed, tumours displaying local lymph node metastasis (stage III) or distant metastasis (stage IV) are more susceptible to form colospheres than are stage I and II tumours.

As colospheres are exclusively formed by cancer cells, they represent a $3 \mathrm{D}$ ex vivo culture model clearly distinct from the 
A

XenoCT320 colospheres

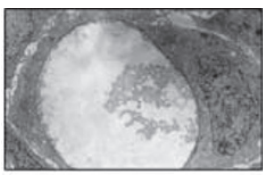

CT320X6

spheroids

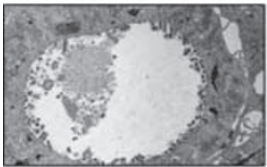

CT320

spheroids

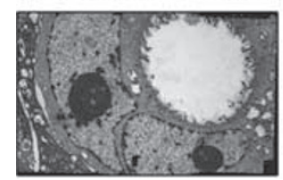

C

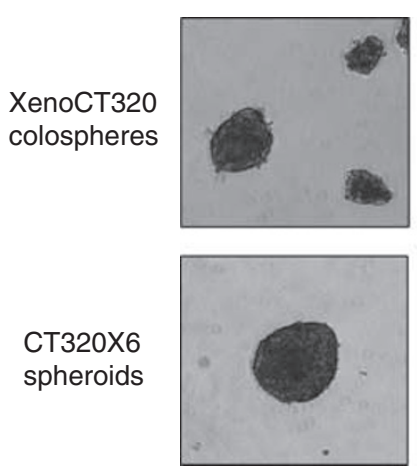

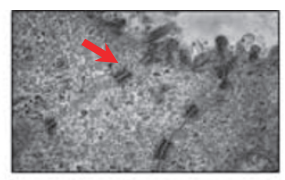
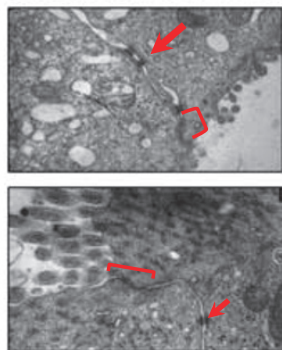

D3

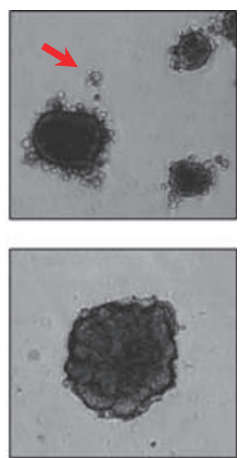

B

XenoCT320

colospheres

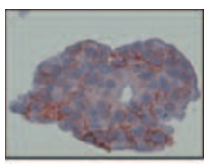

CT320X6

spheroids

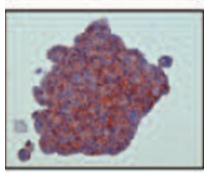

СT320

spheroids

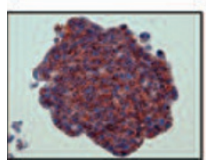

D

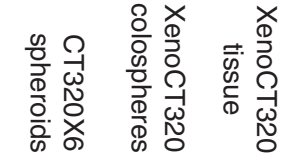

Active MMP-9

Active MMP-2

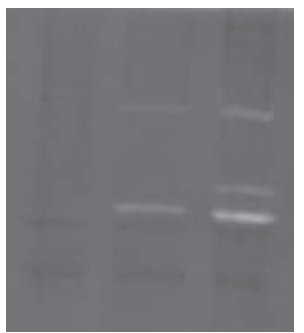

Figure 5 In vitro invasion and migration properties of XenoCT320 colospheres and CT320X6 and CT320 spheroids. These results are from one experiment representative of at least three independent experiments. (A) TEM experiments show acini with microvillosities (left panel), desmosomes (arrows) and zonula occludens (bracket). (B) Anti-E-cadherin immunostaining. Magnification: $\times 20$. (C) XenoCT320 colospheres and CT320X6 spheroids were embedded in Matrigel. Cultures were photographed at days 0 and 3 after embedding. Single-cell motility could be observed with colospheres (red arrow). (D) Results from gelatin zymography. Detection of MMP-2 and MMP-9 activity in lysates of XenoCT320 tissue and in derived colospheres but not in CT320X6 spheroids.

'tumour fragment spheroids' model that consists of a variable mixture of cancer and stromal cells, obtained using the long-term cultivation of tumour biopsy specimens in an organotypic tissue manner (Wibe et al, 1984; Fjellbirkeland et al, 1995). The histological features of colospheres, including high compaction, numerous mitoses and nucleolar atypia, are close to those of both microtumours observed upon cytological analysis of carcinoma ascites and to a lesser extent to those of poorly differentiated spheroids generated with permanent carcinoma cell lines (Santini and Rainaldi, 1999).

To further characterise these colospheres, a large quantity of reproducible biological material was required. To this aim, we used a model based on a human colon cancer xenograft (XenoCT320), able to generate colospheres after ex vivo dissociation, and the derived colon cancer cell lines, CT320 and CT320X6, able to form compact spheroids on agarose. Similarly, we used another pair of xenograft and corresponding cell lines established in the laboratory: the XenoCT329 xenograft established from a human primary colon tumour sample in nude mice, the CT329 cell line established directly from the tumour patient and the CT329X12 cell line derived from XenoCT329 (Dangles-Marie et al, 2007). Colospheres were collected from dissociated XenoCT329 tissue and compared with CT329 and CT329X12 spheroids (data not shown), with comparable results with the CT320 model. This study model provided a unique opportunity to compare colospheres from dissociated CRC xenograft tissue with a conventional 3D multicellular spheroid model, derived from the same tumour specimen. It is noteworthy that the remarkable degree of organisation of colospheres was not dependent on either an exogenous basement membrane or culture within a $3 \mathrm{D}$ matrix, unlike the in vitro spheroid tumour model. Indeed, all dissociation cultures of CRC primary tumours leading here to colospheres were carried out in tissue-culture-treated flasks.

Comparison of morphological structures in colospheres and spheroids in our study model revealed that, despite their compaction, colospheres did not display tight junctions. They also displayed a disturbed expression of E-cadherin, one of the caretakers of the epithelial phenotype, compared with spheroids. Although the role of EMT in carcinoma dissemination is controversial (Christiansen and Rajasekaran, 2006), downregulation of E-cadherin has been linked to invasion and metastasis in CRC (Bates and Mercurio, 2005). These observations suggest that colosphere-forming cells maintain EMT potential. The putative involvement of these cells in cancer spread was underlined by the colospheres' ability to migrate into Matrigel. Indeed, one of the first events that metastatic cells have to complete is the local invasion of stroma, a process that requires a degradation of extracellular matrix components by proteolytic enzymes including MMPs (Fidler, 2002; Pantel and Brakenhoff, 2004). One particular group of MMPs, the gelatinases A and B, also known as MMP-2 and MMP-9, are of particular interest with respect to the development and progression of CRC (Garbett et al, 1999; Mook et al, 2004). Gelatinase analysis showed that ex vivo colospheres displayed MMP-2 and MMP-9 activity, as did parental xenograft tissue, whereas paired cell line spheroids were devoid of such proteases. More importantly, as shown by a subrenal capsule assay, 
A

\begin{tabular}{|c|c|c|c|c|c|}
\hline \multirow[t]{2}{*}{ Colon cancer cell source } & \multirow[t]{2}{*}{$\begin{array}{c}\text { Control } \\
2 \times 10^{6} \text { cells }\end{array}$} & \multicolumn{4}{|c|}{ Kidney capsule injection $4 \times 10^{4}$ cells } \\
\hline & & Kidney & Liver & Lung & Spleen \\
\hline XenoCT320 colospheres & ND & $6 / 15(40 \%)$ & $0 / 15$ & $2 / 15(13 \%)$ & $0 / 15$ \\
\hline CT320X6 spheroids & $3 / 3$ & $0 / 15$ & $0 / 15$ & $0 / 15$ & $0 / 15$ \\
\hline CT320X6 single cells & $3 / 3$ & $1 / 13(8 \%)$ & $0 / 13$ & $0 / 13$ & $0 / 13$ \\
\hline
\end{tabular}

B

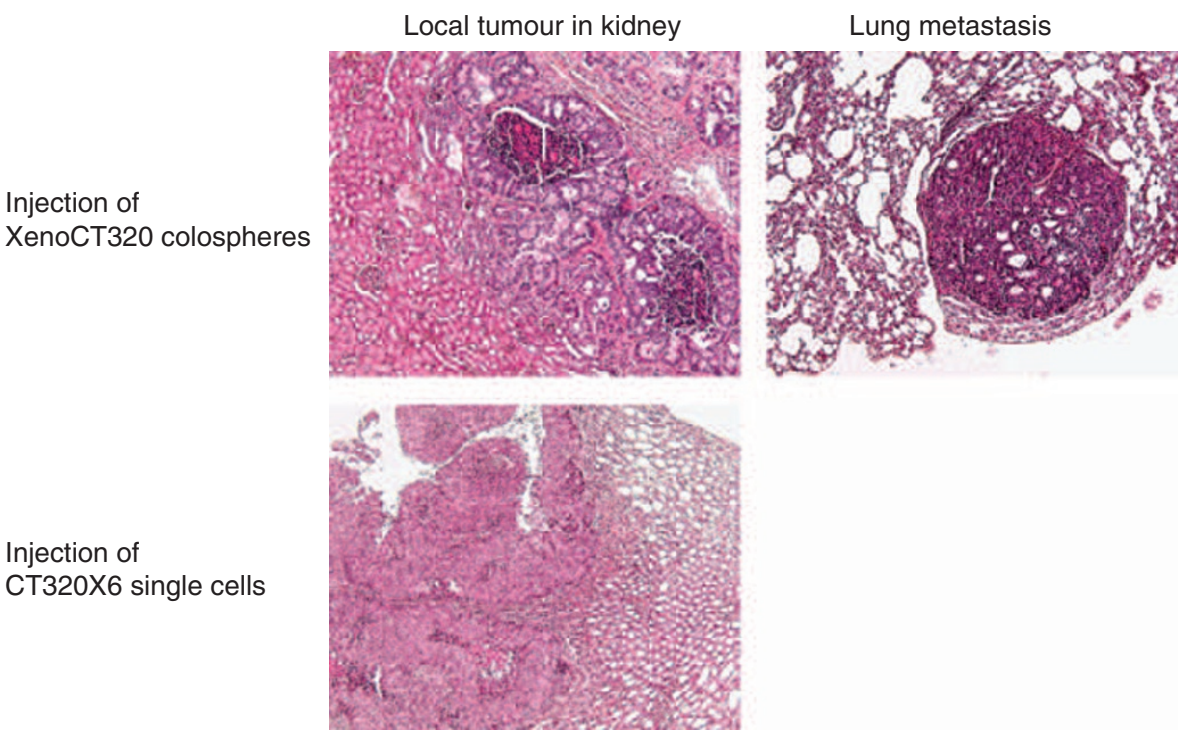

Figure 6 Tumorigenic and metastatic phenotype of XenoCT320 colospheres. (A) Injections of a quantity equivalent to $4 \times 10^{4}$ cells as colospheres, spheroids or single-cell suspension were administered in a subrenal capsule assay in nude mice. After 14 weeks, mice were examined for local and distant tumour development. Mice were considered negative if no tumour tissue was identified either by necropsy or by histological examination. As control, $2 \times 10^{6}$ cells were subcutaneously injected. (B) A well-differentiated colon adenocarcinoma was developed at the kidney site and in the lung after XenoCT320 colosphere injection under renal capsule. A poorly differentiated colon adenocarcinoma was obtained in the kidney of one mouse after injection of CT320X6 single cells. HES staining, magnification $\times 5$.

Table I Expression of CDI33 and CD44 in XenoCT320 xenograft, derived colospheres and CT320X6 and CT320 spheroids

\begin{tabular}{|c|c|c|}
\hline & \multicolumn{2}{|c|}{ Percentage of positive cells } \\
\hline & CDI33 & CD44 \\
\hline $\begin{array}{l}\text { XenoCT320 colospheres } \\
\text { XenoCT320 tissue } \\
\text { CT320X6 spheroids } \\
\text { CT320 spheroids }\end{array}$ & $\begin{array}{l}64.5 \pm 21 \\
57.5 \pm 19 \\
13 \pm 2 \\
25 \pm 11\end{array}$ & $\begin{array}{c}4.4 \pm 2.3 \\
5.7 \pm 6.8 \\
32 \pm 2 \\
32.3 \pm 6.8\end{array}$ \\
\hline
\end{tabular}

Data are means \pm s.e.m. of results from experiments carried out at least three times a Data are given for EpCAM ${ }^{+}$cells sorted from XenoCT320 tissue.

colospheres displayed undoubtedly a high tumorigenicity and metastatic potential, compared with the spheroid model, suggesting that these 3D structures contained more cancer-initiating cells. It could be hypothesised that the different tumorigenicity is related to a higher passage number into mice for xenografts giving rise to colospheres than for xenografts leading to the CT320X6 cell line. Nevertheless, the presumed selection of more aggressive cells through in vivo passage is not so clear. We have determined that the CT320 cell line, established directly from a patient sample without any passage into mice, and the CT320X6 cell line, derived from the xenograft XenoCT320, display a similar growth curve in nude mice (unpublished data). It is also noteworthy that tumours obtained after injection of colospheres were well-differentiated adenocarcinomas, whereas tumours derived from a cell-suspension injection were poorly differentiated carcinomas, illustrating, as largely observed (personal communication, Heiner Fiebig), that cancer cell lines established from differentiated human tumours lead to poorly differentiated tumours, whereas xenografts directly from tissue tumour specimens maintain their differentiation level. The differences observed between colospheres and spheroids have to be put in line with the different growth conditions (ex vivo vs in vitro), which in turn involve different microenvironments. The impact of the microenvironment - such as cell-cell interactions and extracellular matrix - on cell phenotype is indeed well described (Santini and Rainaldi, 1999; Jacks and Weinberg, 2002; O'Brien et al, 2002; Smalley et al, 2006; Friedrich et al, 2007).

Owing to their round compact architecture and their direct CRC tissue origin, colospheres can be compared with colon cancer spheres, a model previously described for colon cancer stem cell expansion cultures (Ricci-Vitiani et al, 2007; Todaro et al, 2008; Vermeulen et al, 2008). However, methods for obtaining colospheres and colon cancer spheres clearly differ. Indeed, colospheres are formed after a simple mechanical dissociation 
protocol, preserving small pieces in cultured tumour bulk, whereas colon cancer spheres are generated after an enzymatic treatment leading to a single-cell suspension. In addition, colon cancer spheres require ultra-low-attachment conditions, epidermal growth factor and fibroblast growth factor-2, plus culture for 4 weeks, whereas colospheres form in 1 day, without adding exogenous growth factors. Furthermore, these two models also differ by the expression profile of putative colon cancer stem cell markers. CD133 has been reported to be a presumed colon cancer stem cell marker (O'Brien et al, 2007; Ricci-Vitiani et al, 2007; Todaro et al, 2008), even if this function is now challenged (LaBarge and Bissell, 2008; Shmelkov et al, 2008), and CD44 has been more convincingly described as an informative marker of colon cancer stem cells in both primary tumours and xenografts (Dalerba et al, 2007; Subramaniam et al, 2007; Du et al, 2008). Although cells grown as undifferentiated colon cancer spheres have been reported to be exclusively $\mathrm{CD}_{133}{ }^{+}$(Ricci-Vitiani et al, 2007), a large number of cells from colospheres expressed CD133, but a negative population was also present. These results are consistent with a recent study describing a variable pattern of CRC tumours that were negative to highly positive for CD133 expression (Dalerba et al, 2007). Likewise, the rates of $\mathrm{CD} 44^{+}$ human cells in the xenograft and the fact that $\mathrm{CD} 44^{+}$cells were a minority sub-population of $\mathrm{CD}_{133^{+}}$cells are consistently in agreement with previous observations by Clarke and Coll (Dalerba et al, 2007). Therefore, colospheres closely reproduce the CD44 and CD133 expression profiles found in the parental xenograft.

In conclusion, these results show that colospheres form an ex vivo three-dimensional model distinct from traditional spheroids. It is noteworthy that colospheres are formed from a random dissociation of fragments of tumours, leading to potential variability within resulting colospheres. In contrast, spheroids are obtained from cell lines using the liquid overlay technique in microwells, giving rise to a population of identical spheroids. This heterogeneity in the colosphere population could reflect inherent intratumoral heterogeneity. As a short-term culture model associated with tumour aggressiveness, it might therefore be relevant for studying metastatic processes.

\section{ACKNOWLEDGEMENTS}

We are grateful to the personnel of the Département d'Anatomie Pathologique, Institut Mutualiste Montsouris, for help in collecting primary cancer tissues and to $\mathrm{F}$ Assayag for xenograft passage, and to animal facility people managed by $\mathrm{C}$ Martin. We are especially thankful to L Larue for exciting discussions on colospheres and to L Aldaz-Carroll for critical review of the manuscript. This study was supported by Ligue Contre le Cancer, Comite Ile-de-France (Grant RS 06/75-71, RS 07/75-45); Institut National du Cancer et Cancérôpole Ile de France ('COLOMETASTEM' and CSC cross platform network projects); Philippe and Denis Bloch Cancer Research Grant, Patrick Roy Translational Medicine Grant and Laura Mentzelopoulos Translational Research Grant. LBW was supported by predoctoral fellowships from the Association d'Aide à la Recherche Cancérologique de Saint-Cloud.

Supplementary Information accompanies the paper on British Journal of Cancer website (http://www.nature.com/bjc)

\section{REFERENCES}

Bates RC, Mercurio AM (2005) The epithelial-mesenchymal transition (EMT) and colorectal cancer progression. Cancer Biol Ther 4: 365-370

Bjerkvig R, Hostmark J, Pedersen PH, Laerum OD (1992) Tumor spheroids from biopsy specimens. In Spheroid Culture in Cancer Research, Bjerkvig R (ed), pp 41-56. CRC Press: Boca Raton

Briffod M, Hacène K, Le Doussal V (2000) Immunohistochemistry on cell blocks from fine-needle cytopunctures of primary breast carcinomas and lymph node metastases. Mod Pathol 8: $841-850$

Christiansen JJ, Rajasekaran AK (2006) Reassessing epithelial to mesenchymal transition as a prerequisite for carcinoma invasion and metastasis. Cancer Res 66: 8319-8326

Dalerba P, Dylla SJ, Park IK, Liu R, Wang X, Cho RW, Hoey T, Gurney A, Huang EH, Simeone DM, Shelton AA, Parmiani G, Castelli C, Clarke MF (2007) Phenotypic characterization of human colorectal cancer stem cells. Proc Natl Acad Sci USA 104: 10158-10163

Dangles-Marie V, Pocard M, Richon S, Weiswald LB, Assayag F, Saulnier P, Judde JG, Janneau JL, Auger N, Validire P, Dutrillaux B, Praz F, Bellet D, Poupon MF (2007) Establishment of human colon cancer cell lines from fresh tumors $v s$ xenografts: comparison of success rate and cell line features. Cancer Res 67: 398-407

Debnath J, Brugge JS (2005) Modelling glandular epithelial cancers in threedimensional cultures. Nat Rev Cancer 5: 675-688

Du L, Wang H, He L, Zhang J, Ni B, Wang X, Jin H, Cahuzac N, Mehrpour M, Lu Y, Chen Q (2008) CD44 is of functional importance for colorectal cancer stem cells. Clin Cancer Res 14: 6751-6760

Fearon ER, Vogelstein B (1990) A genetic model for colorectal tumorigenesis. Cell 61: 759-767

Fidler IJ (2002) Critical determinants of metastasis. Semin Cancer Biol 12: $89-96$

Fjellbirkeland L, Bjerkvig R, Laerum OD (1995) Tumour fragment spheroids from human non-small-cell lung cancer maintained in organ culture. Virchows Arch 426: 169-178

Friedrich J, Ebner R, Kunz-Schughart LA (2007) Experimental anti-tumor therapy in 3-D: spheroids-old hat or new challenge? Int J Radiat Biol 83: 849-871

Garbett EA, Reed MW, Brown NJ (1999) Proteolysis in colorectal cancer. Mol Pathol 52: 140-145
Jacks T, Weinberg RA (2002) Taking the study of cancer cell survival to a new dimension. Cell 111: 923-925

LaBarge MA, Bissell MJ (2008) Is CD133 a marker of metastatic colon cancer stem cells? J Clin Invest 118: 2021 - 2024

Lévy P, Bièche I, Leroy K, Parfait B, Wechsler J, Laurendeau I, Wolkenstein P, Vidaud M, Vidaud D (2004) Molecular profiles of neurofibromatosis type 1-associated plexiform neurofibromas: identification of a gene expression signature of poor prognosis. Clin Cancer Res 10: $3763-3771$

McBain JA, Weese JL, Meisner LF, Wolberg WH, Willson JK (1984) Establishment and characterization of human colorectal cancer cell lines. Cancer Res 44: 5813-5821

Mook OR, Frederiks WM, Van Noorden CJ (2004) The role of gelatinases in colorectal cancer progression and metastasis. Biochim Biophys Acta 1705: 69-89

O'Brien CA, Pollett A, Gallinger S, Dick JE (2007) A human colon cancer cell capable of initiating tumour growth in immunodeficient mice. Nature 445: $106-110$

O'Brien LE, Zegers MM, Mostov KE (2002) Opinion: Building epithelial architecture: insights from three-dimensional culture models. Nat Rev Mol Cell Biol 3: $531-537$

Oh JH, Ku JL, Yoon KA, Kwon HJ, Kim WH, Park HS, Yeo KS, Song SY, Chung JK, Park JG (1999) Establishment and characterization of 12 human colorectal-carcinoma cell lines. Int J Cancer 81: 902-910

Pantel K, Brakenhoff RH (2004) Dissecting the metastatic cascade. Nat Rev Cancer 4: 448-456

Park JG, Oie HK, Sugarbaker PH, Henslee JG, Chen TR, Johnson BE, Gazdar A (1987) Characteristics of cell lines established from human colorectal carcinoma. Cancer Res 47: 6710-6718

Ribadeau Dumas A, Hamouda NB, Leriche L, Piffaut MC, Bonnemye P, Kuen RL, Tricottet V, Merle-Beral H, N'Guyen Khac F, Arock M (2004) Establishment and characterization of a new human erythroleukemic cell line, ERY-1. Leuk Res 28: 1329-1339

Ricci-Vitiani L, Lombardi DG, Pilozzi E, Biffoni M, Todaro M, Peschle C, De Maria R (2007) Identification and expansion of human colon-cancerinitiating cells. Nature 445: 111-115 
Santini MT, Rainaldi G (1999) Three-dimensional spheroid model in tumor biology. Pathobiology 67: 148-157

Shmelkov SV, Butler JM, Hooper AT, Hormigo A, Kushner J, Milde T, St Clair R, Baljevic M, White I, Jin DK, Chadburn A, Murphy AJ, Valenzuela DM, Gale NW, Thurston G, Yancopoulos GD, D'Angelica M, Kemeny N, Lyden D, Rafii S (2008) CD133 expression is not restricted to stem cells, and both CD133+ and CD133- metastatic colon cancer cells initiate tumors. J Clin Invest 118: 2111-2120

Smalley KS, Lioni M, Herlyn M (2006) Life isn't flat: taking cancer biology to the next dimension. In Vitro Cell Dev Biol Anim 42: 242-247

Subramaniam V, Vincent IR, Gilakjan M, Jothy S (2007) Suppression of human colon cancer tumors in nude mice by siRNA CD44 gene therapy. Exp Mol Pathol 83: 332-340

Svendsen CN, ter Borg MG, Armstrong RJ, Rosser AE, Chandran S, Ostenfeld T, Caldwell MA (1998) A new method for the rapid and long term growth of human neural precursor cells. J Neurosci Methods 85: 141-152
Todaro M, Alea MP, Di Stefano AB, Cammareri P, Vermeulen L, Iovino F, Tripodo C, Russo A, Gulotta G, Medema JP, Stassi G (2007) Colon cancer stem cells dictate tumor growth and resist cell death by production of interleukin-4. Cell Stem Cell 1: 389-402

Todaro M, Perez Alea M, Scopelliti A, Medema JP, Stassi G (2008) IL-4-mediated drug resistance in colon cancer stem cells. Cell Cycle 7: $309-313$

Vermeulen L, Todaro M, de Sousa Mello F, Sprick MR, Kemper K, Perez Alea M, Richel DJ, Stassi G, Medema JP (2008) Single-cell cloning of colon cancer stem cells reveals a multi-lineage differentiation capacity. Proc Natl Acad Sci USA 105: $13427-13432$

Wibe E, Berg JP, Tveit KM, Nesland JM, Lunde S (1984) Multicellular spheroids grown directly from human tumour material. Int J Cancer 34: $21-26$

Yamada KM, Clark K (2002) Cell biology: survival in three dimensions. Nature 419: $790-791$ 